\title{
Scientific output of the emerging Cuban biopharmaceutical industry: a scientometric approach
}

\author{
Ricardo Arencibia-Jorge ${ }^{1}$ (D) Elena Corera-Alvarez ${ }^{2}$ • \\ Zaida Chinchilla-Rodríguez ${ }^{2}$ - Félix de Moya-Anegón ${ }^{2}$
}

Received: 19 May 2016/Published online: 25 June 2016

(c) Akadémiai Kiadó, Budapest, Hungary 2016

\begin{abstract}
Cuba has developed a biopharmaceutical sector that involves some of the country's most relevant scientific institutions. Despite the severe constraints on resources resulting from the U.S. embargo, the results achieved by this sector have contributed to put the country's health indicators at the same level of high-income nations. Recently, the creation of BioCubaFarma as a cluster of high-technology enterprises organized around a closed cycle model becomes one of the most relevant efforts of the Island in order to make biopharmaceuticals one of the country's leading export earners. The main aim of the current paper was to characterize BioCubaFarma through a battery of Scopus-based bibliometric indicators. A comparison with the most productive multinational pharmaceutical companies was made. Regression analysis of annual productivity, number of citations, scientific talent pool, innovative knowledge and other citation-based indicators was performed. Differences and similarities between BioCubaFarma and multinational companies in four Scopus subject categories related to this sector were identified. The most productive and visible institutions from BioCubaFarma were also characterized. Qualified human resources, innovative knowledge, leadership, high specialization in the field of vaccines development and non-dependence of international collaboration are strengths of the organization. However, it is still necessary to increase the number of articles published in highly visible journals with the aim to achieve a better citation-based performance.
\end{abstract}

Ricardo Arencibia-Jorge

ricardo.arencibia@cnic.edu.cu

Elena Corera-Alvarez

elena.corera@csic.es

Zaida Chinchilla-Rodríguez

zaida.chinchilla@csic.es

Félix de Moya-Anegón

felix.moya@scimago.es

1 National Center for Scientific Research (CNIC), Ave. 25 y Calle 158, Cubanacán, Playa, AP 6414, Havana, Cuba

2 SciMago Research Group, Institute of Policies and Public Goods, CCHS-CSIC, Madrid, Spain 
Moreover, to increase the contributions from less-productive institutions, more clinical research published in medical journals and more collaboration with universities and health institutions could also have positive benefits for BioCubaFarma's pipelines and portfolios.

Keywords Biopharmaceuticals - Pharmaceutical industry - Scientometrics - Bibliometric indicators · Leadership · Excellence · International collaboration · Multinational companies $\cdot$ Cuba

\section{Introduction}

Far from the monopoly of media, and despite the severe constraints on resources resulting from the US embargo, Cuba has developed a biopharmaceutical sector that involves some of the country's most relevant scientific institutions. The results achieved by this sector have contributed to put the country's health indicators at the same level of high-income nations, with extraordinary success in low infant, child and maternal mortality rates and healthy-live expectancy (Cooper et al. 2006; Lage 2008; Sáenz 2005).

From a scientometric perspective Cuban scientific output at macro level have been recently analysed (Araujo-Ruiz et al. 2005; Arencibia-Jorge and de Moya-Anegón 2010; Chinchilla-Rodríguez et al. 2015), with emphasis in literature on health science (ArencibiaJorge et al. 2012; Cañedo Andalia et al. 2010, 2014; Zacca-González et al. 2014, 2015). However, none of them have been focused on topics related to biotechnology and the pharmaceutical sector, or specifically dedicated to analyse the Cuban biopharmaceutical industry, recently improved since the creation of BioCubaFarma as a new cluster of hightechnology enterprises belonging to this sector.

The pharmacological domain has been studied with high frequency by bibliometric studies, due to the important medical and economic repercussions of research in this area. At country level, Bordons and colleagues studied the Spanish scientific output, using a citation-based indicator (the Expected Impact Factor) to identify the potential influence of Spanish research on the international scientific community (Bordons et al. 1996, 1998; Bordons and Zulueta 1997). They found during the nineties the subfield Pharmacology and Pharmacy in a very dynamic stage, with a great increase in the number of researchers, starting of new teams and consolidation of others (Bordons et al. 1998).

Biochemistry and Molecular Biology and Pharmacology and Pharmacy were among the three most productive research fields in the Spanish biomedical research (Cami et al. 1997; Gomez et al. 2004). This protagonist role of pharmacological research was also identified in Iran (Mohammadhassanzadeh et al. 2010). Ammed et al. (2014) analyzed the Indian pharmacological research using Scopus as data source, and comparing the Indian performance with the scientific output of the 15 most productive countries. In the same way, Ding et al. (2013) evaluated the productivity of China during the first decade of the twenty first century in relation to ten representative countries. In UK, Science Parks and Research Parks were identified as successful infrastructures in fostering cooperation and research production, with strong links to universities (Minguillo et al. 2015).

Patent research using bibliometric methods in the context of the pharmaceutical industry were remarked by Huang et al. (2011). Some studies applied non citation-based indicators to analyze pharmaceutical domains in order to assess the probability of drug success (Kissin and Bradley 2011, 2012), or publication trends of pharmaceutical science faculty 
members at research-intensive colleges and schools of pharmacy (Thompson and Nahata 2012). Although, comparative studies of Scopus and Web of Science to evaluate Pharmacy Journals have been developed (Gorraiz and Schloegl 2008). However, internationalization processes and cooperation patterns have receiving wide attention during the last 10 years from a scientometric perspective (Calero et al. 2007; Cantner and Rake 2014; Natsukawa et al. 2013; Olmeda-Gomez et al. 2008; Perianes-Rodriguez et al. 2011; Tijssen 2009; Zhao and Guan 2011).

The important role of private enterprises in scientific development and innovation (Perianes-Rodriguez et al. 2011), the central position of US companies in pharmacological research (Calero et al. 2007; Tijssen 2009), the intra- and inter-organizational patterns of research cooperation linkages (Calero et al. 2007; Natsukawa et al. 2013), and the university-enterprise-government inter-relationships (Olmeda-Gomez et al. 2008), were topics analyzed in these studies, where largest multinational pharmaceutical companies have been protagonists.

During the last 30 years, Cuba developed a strong pharmaceutical industry focused in biotechnology products, generics and alternative medicines. The industry was organized around a closed cycle model, whereby research, development, production, marketing, and follow-up evaluations for a given product are carried out within the same administrative unit (Lage 2006, 2008).

The foundation of the National Center for Scientific Research (CNIC) in 1965 was the first step in this race. The developing of qualified human resources was the main aim of CNIC's laboratories, where most of the current Cuban biotech leaders started their research activities. In 1981 a team of Cuban scientists trained by Dr. Kari Cantell (Finland) developed the capacity to isolate Interferon from human cells in large quantities, and the government established the Biological Front, an interdisciplinary forum to facilitate de development of Cuban biotechnology (Lopez et al. 2007; López Mola et al. 2006; Sáenz 2005).

From 1986 to 1990 important scientific centers were inaugurated, as the Center for Genetic Engineering and Biotechnology (CIGB, 1986), the Center of Immunoassay (CIE, 1987), the Finlay Institute (IFinlay, 1991), the Center for Molecular Immunology (CIM, 1994), among others. All these institutions were integrated in the Western Havana Scientific Pole, a cluster of 52 institutions and enterprises related to biotechnology that received from the government an invest of more than $\$ 1$ billion dollars during the worst economic crisis of the country, after the collapse of the Soviet Union (Castillo et al. 2013; Pérez Ones and Jover 2009).

This biocluster achieved relevant results during the next two decades: the worlds first vaccine against Meningitis B, a cholesterol-lowering drug derived from sugarcane without side effects (PPG), a vaccine against recombinant Hepatitis B, a recombinant streptokinase product obtained from DNA for used in acute myocardial infarctions, the worlds first synthetic vaccine against Haemophilus influenzae type B (Quimi-Hib), and recently, therapeutic cancer vaccines based on monoclonal antibodies (CimaVax-EGT, Theraloc, etc.), and a recombinant growth factor used in the treatment of diabetic foot ulcers (Heberprot-PE).

In 2013, the West Havana biocluster and Quimefa, the most important Cuban pharmaceutical company, were integrated to create BioCubaFarma. In the context of the Cuban economic model reform, this strategic fusion improved the structure of the Cuban biotechnological and pharmaceutical industry. The aim is not only to enhance the coverage of national drug demands, but also to create solid worldwide partners and distributors, to introduce products in new markets, and to increase the sales over five billion dollars in the 
near future, which is probably to make biopharmaceuticals the country's leading export earner.

Despite the economic revenues obtained from the sales of its products, the research philosophy of BioCubaFarma's project is diametrically opposed to the market policies of the big pharmaceutical industry. First, the priority is to maintain the country's health standards, minimizing Cuba's dependency on pharmaceutical imports (Lage 2006, 2008). On the other hand, whereas de dominant practice among larger pharmaceutical companies in industrialized countries is to outsource manufacturing, the Cuban system maintains local production facilities, creating additional employment opportunities at home. Also, the Cuban biopharmaceutical industry hardly uses money for publicity, which is an activity with high expenses in budgets of multinational corporations (Castillo et al. 2013; Lage 2006).

The main aim of the current paper is to characterize the scientific production of BioCubaFarma during a pre-foundational period (2003-2013). BioCubaFarma's performance is analysed at national level, and it is compared with the performance of the 15 most productive multinational pharmaceutical companies. A battery of Scopus-based bibliometric indicators to analyse activity, specialization, impact, collaboration, leadership, and excellence of these institutions, is used. Differences and similarities are identified and discussed.

\section{Materials and methods}

The SCImago Institutions Rankings (SIR), based on Scopus data and developed by the SCIMago Research Group (Spain), was used to retrieve output developed by Cuban institutions with more than 25 published papers per year. The whole output of BioCubaFarma and the scientific production of its most productive institutions were also retrieved. For comparative purposes, data of the 15 most productive multinational pharmaceutical companies were compiled, using not only global output, but also the performance of each institution in the following Scopus subject categories:

- Pharmacology, Toxicology \& Pharmacy (PTP)

- Immunology and Microbiology (I\&M)

- Biochemistry, Genetics \& Molecular Biology (BG\&MB)

- Medicine

A set of bibliometric indicators, most of them developed by the SCImago Research Group, were used to analyze scientometric characteristics of the studied institutions:

Output (Ndoc): Total number of documents published in scholarly journals indexed in Scopus.

Annual Productivity (AP): Total number of documents published per year during the period 2003-2013.

Citations (Ncit): Total number of citations received by all documents published in scholarly journals indexed in Scopus.

Cited documents (\% Cited doc): Percentage of documents with at least one citation received during the period 2003-2013.

International Collaboration (\% Int Coll): Institution's output ratio produced in collaboration with foreign institutions. The values are computed by analyzing an institution's 
output whose affiliations include more than one country address (Guerrero-Bote et al. 2013).

Normalized Impact (NI): Normalized Impact of led output is computed using the methodology established by the Karolinska Intitutet in Sweden where it is named "Item oriented field normalized citation score average". The normalization of the citation values is done on an individual article level (Rehn et al. 2007). The values (in decimal numbers) show the relationship between an institution's average scientific impact and the world average set to a score of 1 , -i.e. a NI score of 0.8 means the institution is cited $20 \%$ below world average and 1.3 means the institution is cited $30 \%$ above average.

High Quality Journals (\% Q1): Ratio of publications that an institution publishes in the most influential scholarly journals of the world, those ranked in the first quartile (25\%) in their categories as ordered by SCImago Journal Rank (SJRII) indicator.

Excellence (\% Exc): Excellence rate that indicates the amount (in \%) of an institution's scientific output that is included into the set of the $10 \%$ of the most cited papers in their respective scientific fields. It is a measure of high quality output of research institutions (Bornmann et al. 2012).

Leadership (\% Lead): Leadership rate that indicates the percentage of an institution's output as main contributor, that is, the amount of papers in which the corresponding author belongs to the institution (Moya-Anegon et al. 2013).

Excellence with Leadership (\% EwL): Excellence with Leadership indicates the amount of documents in the Excellence rate in which the institution is the main contributor.

Scientific Talent Pool (STP): Total number of authors from an institution in the total publication output of that institution during a particular period of time.

Innovative Knowledge (IK): Scientific publication output from an institution cited in patents. Based on PATSTAT (http://www.epo.org).

Specialization Index (Spec): Based on the activity index (Frame 1977), it is calculated to identify thematic specialization of institutions through the following procedure:

$$
\mathrm{Spec}=\left(\mathrm{Ndoc}_{\text {company (domain) }} / \mathrm{Ndoc}_{\text {company (total) }}\right) /\left(\mathrm{Ndoc}_{\text {company (domain) }} / \mathrm{Ndoc}_{\text {company (total) }}\right)
$$

Attractivity Index (AI): Based on the countries' Attractivity Index (Braun and Schubert 1997), it is calculated to determine the visibility of companies through the following procedure:

$$
\mathrm{AI}=\left(\mathrm{Ncit}_{\text {company (domain) }} / \mathrm{Ncit}_{\text {company (total) }}\right) /\left(\mathrm{Ncit}_{\text {company (domain) }} / \mathrm{Ncit}_{\text {company (total) }}\right)
$$

In the last two indicators, values higher than 1 express more specialization and visibility of companies in the analyzed domains with respect to the world. To facilitate the representation of specialization and attractivity indexes, a scale of values between -1 and 1 were used (Glanzel 2000), where the 0 value is the position of the world in the studied thematic domains.

Microsoft Excel graphs were used to compare companies' performances, and regression patterns among the global indicators of the studied companies were analyzed. Finally, an analysis of the most productive institutions belonging to BioCubaFarma was made, in order to check which of them are determinant in the global BioCubaFarma's performance. 


\section{Results and discussion}

The biopharmaceutical sector has been a protagonist role in Cuban scientific output during more than a decade. Organizations belonging to BioCubaFarma generated 2908 articles published in Scopus-indexed journals during the period 2003-2013, which allowed this company to reach the second position at national level in the SciMago Institutions Rankings (SIR), just 2 years after its foundation (Table 1).

BioCubaFarma shown a productivity of around 264 papers per year, only behind the University of Havana (UH), all-time leader of Cuban scientific activity (Araujo-Ruiz et al. 2005; Arencibia-Jorge and de Moya-Anegón 2010; Sancho et al. 1993). The $62 \%$ of the scientific articles were cited. International collaboration involve only $30.81 \%$ of papers, while $68.23 \%$ had researchers from BioCubaFarma's institutions as corresponding authors.

In the context of the Cuban most productive institutions during the studied period (more than 25 papers per year), BioCubaFarma achieved the eighth position in high cited articles (\% Exc), and the fifth position according to the impact of research (NI), publication in high visible journals (\% Q1), and leadership of the most cited articles (\% EwL). These citationbased indicators are leaded by universities from Matanzas (Universidad de Matanzas "Camilo Cienfuegos", UMCC) and Villa Clara (Universidad Central de Las Villas, UCLV), which were clearly the most visible Cuban institutions (Fig. 1). In almost all university cases, with the solely exception of the Instituto Superior de Ciencias Médicas de La Habana (ISCMH), international collaboration is determinant to reach good citationbased performances.

Compared with the most productive Cuban institutions, BioCubaFarma's behaviour exposed characteristics that become strengths. First, visibility was not dependent of the international collaboration (similar to the Instituto de Medicina Tropical "Pedro Kourí", IPK), which is an evidence of the protagonist role of BioCubaFarma's companies in the sector development. Second, it was the leader according STP indicator, which implies that many researchers from BioCubaFarma are involved in published articles. Third, it was

Table 1 Scientometric performance of the Cuban most productive institutions (Scopus, 2003-2013)

\begin{tabular}{lrrrlllllllllr}
\hline & Ndoc & AP & Ncit & $\begin{array}{l}\% \text { Cited } \\
\text { doc }\end{array}$ & $\begin{array}{l}\% \text { Int } \\
\text { Coll }\end{array}$ & NI & $\begin{array}{l}\% \\
\text { Q1 }\end{array}$ & $\begin{array}{l}\% \\
\text { Exc }\end{array}$ & $\begin{array}{l}\% \\
\text { Lead }\end{array}$ & $\begin{array}{l}\% \\
\text { EwL }\end{array}$ & STP & IK \\
\hline UH & 2993 & 272.1 & 18,824 & 63.78 & 66.46 & 0.55 & 37.05 & 5.35 & 44.27 & 1.24 & 2137 & 42 \\
BCF & 2908 & 264.4 & 22,285 & 62.00 & 30.81 & 0.51 & 28.71 & 4.26 & 68.23 & 2.06 & 4079 & 113 \\
ISCMH & 1353 & 123.0 & 2186 & 20.33 & 13.67 & 0.16 & 7.24 & 1.55 & 64.6 & 0 & 1740 & 1 \\
UCLV & 1141 & 103.7 & 8887 & 59.33 & 64.5 & 0.73 & 30.94 & 12.1 & 55.74 & 6.57 & 1084 & 13 \\
IPK & 1064 & 96.7 & 7571 & 58.18 & 32.42 & 0.48 & 23.4 & 5.36 & 69.74 & 1.88 & 1202 & 13 \\
HHA & 666 & 60.5 & 1149 & 23.12 & 10.21 & 0.11 & 5.26 & 1.2 & 66.67 & 0.15 & 1023 & 4 \\
UO & 639 & 58.1 & 2711 & 60.56 & 73.55 & 0.5 & 27.23 & 6.73 & 53.36 & 2.5 & 561 & 9 \\
ICA & 577 & 52.5 & 495 & 39.51 & 23.22 & 0.11 & 1.73 & 0 & 77.47 & 0 & 340 & 0 \\
CUJAE & 494 & 44.9 & 1753 & 45.95 & 65.79 & 0.47 & 24.49 & 6.68 & 42.91 & 0.81 & 464 & 3 \\
ICIMAF & 335 & 30.5 & 1508 & 61.79 & 72.24 & 0.53 & 36.12 & 6.87 & 45.07 & 2.69 & 163 & 0 \\
UMCC & 307 & 27.9 & 3541 & 72.31 & 68.08 & 1.01 & 39.74 & 13.7 & 63.52 & 5.54 & 185 & 13 \\
IHI & 281 & 25.5 & 273 & 19.22 & 5.34 & 0.06 & 3.2 & 0.36 & 84.34 & 0 & 365 & 1 \\
\hline
\end{tabular}




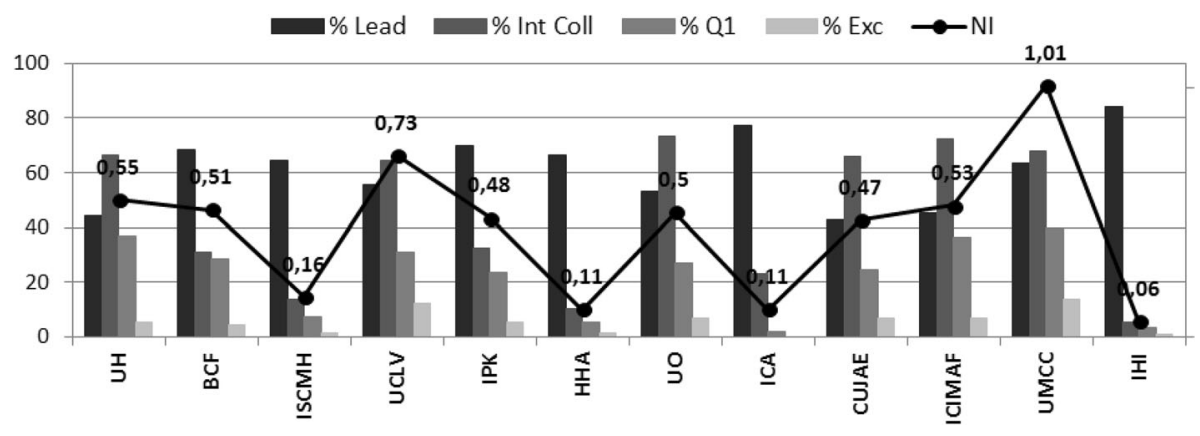

Fig. 1 Leadership, international collaboration, output in high visible journals, excellence and normalized impact of the most productive Cuban institutions (Scopus, 2003-2013)

leader according to the IK index, thanks to a total of 113 BioCubaFarma's papers cited by international patents. On the other hand, similar characteristics were observed in leadership, where Cuban institutions shown higher percentages.

Another picture is offered by the comparison of BioCubaFarma with the 15 most productive multinational biopharmaceutical companies (Table 2). While $28 \%$ of BioCubaFarma's scientific literature was published in high visible journals (Q1 of Scopus), multinationals shown values over $60 \%$. This behaviour had a clear repercussion on the impact values. The range of excellence (20-30\%), excellence with leadership (5-10\%), cited papers $(>80 \%)$ and normalized impact $(1.5-2.6)$ in multinationals are clearly higher than BioCubaFarma's values (4.26; 2.06; $62 \%$; and 0.51 respectively).

Low international collaboration value is a characteristic that share BioCubaFarma with multinationals. But it is in leadership when BioCubaFarma revealed a significant difference with the international competence. To be the leader of research is an advantage for BioCubaFarma. But the strategies of multinational companies have also positive benefits on $\mathrm{R} \& \mathrm{D}$ results. The percentage of non-leaded papers of these companies is distributed among research departments of universities, university hospitals or private clinics where they invest a proportion of their R\&D budget. This politics ensure advances not only in the growth of new research lines and products, but also in the acquisition of qualified human resources for companies. Therefore, to sacrifice leadership in order to create strong links with universities to enhance pipelines and research portfolios is a positive way, and must be used with most frequency by BioCubaFarma's enterprises.

The size factor put in evidence the positive linear relationship between annual productivity, number of citations, scientific talent pool and innovative knowledge (Fig. 2). However, it is clear the classic link between expected and real visibility: higher the percentage of articles published in Q1 journals is, higher is also the percentage of articles among the most cited literature of a discipline, and the normalized impact of the whole scientific output.

The analysis of the most covered subject categories in BioCubaFarma's literature offers new interesting trends (Figs. 3, 4). The Cuban biocluster shares specialization (activity index) and visibility (attractivity index) patterns with multinational companies in the fields of PTP and BG\&MB, which illustrate its advances in pharmaceuticals and biotechnologybased products (Fig. 3). I\&M is the subject category where BioCubaFarma is absolute leader, thanks to the protagonist role of therapeutic vaccines in the company's pipeline. But 


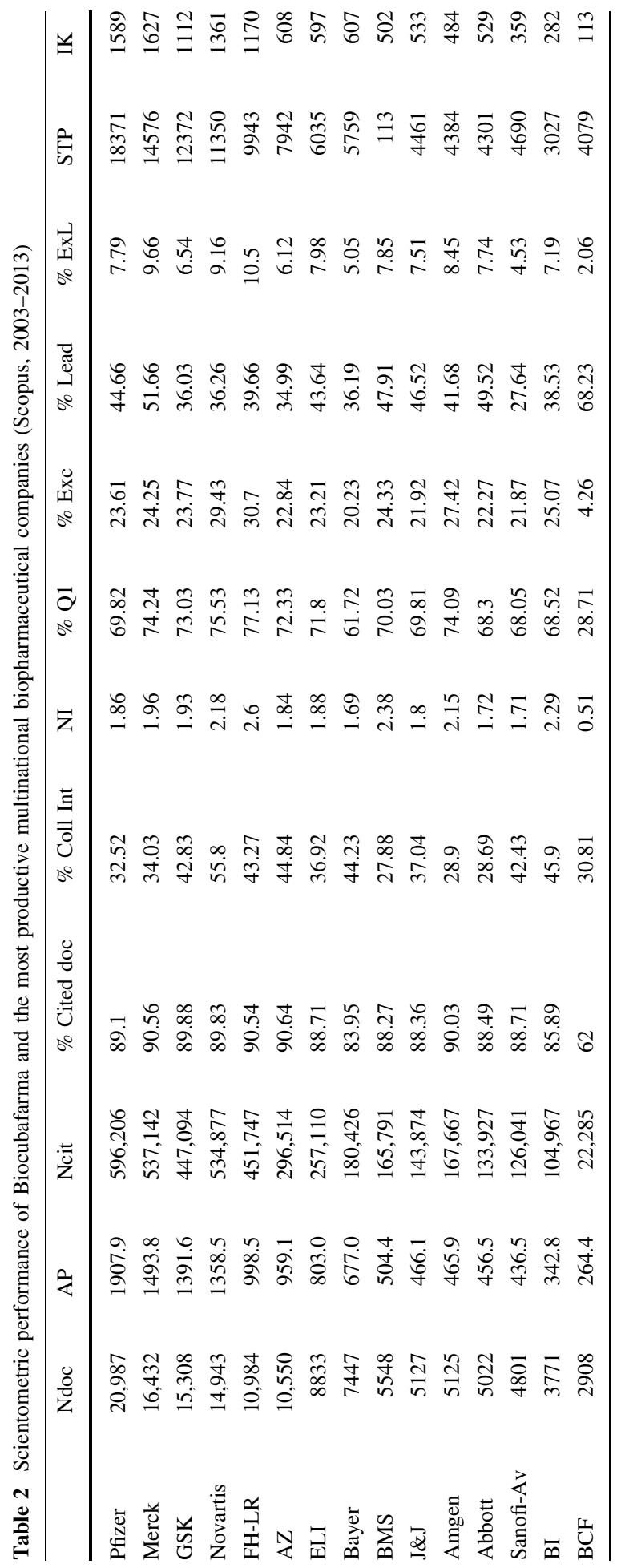



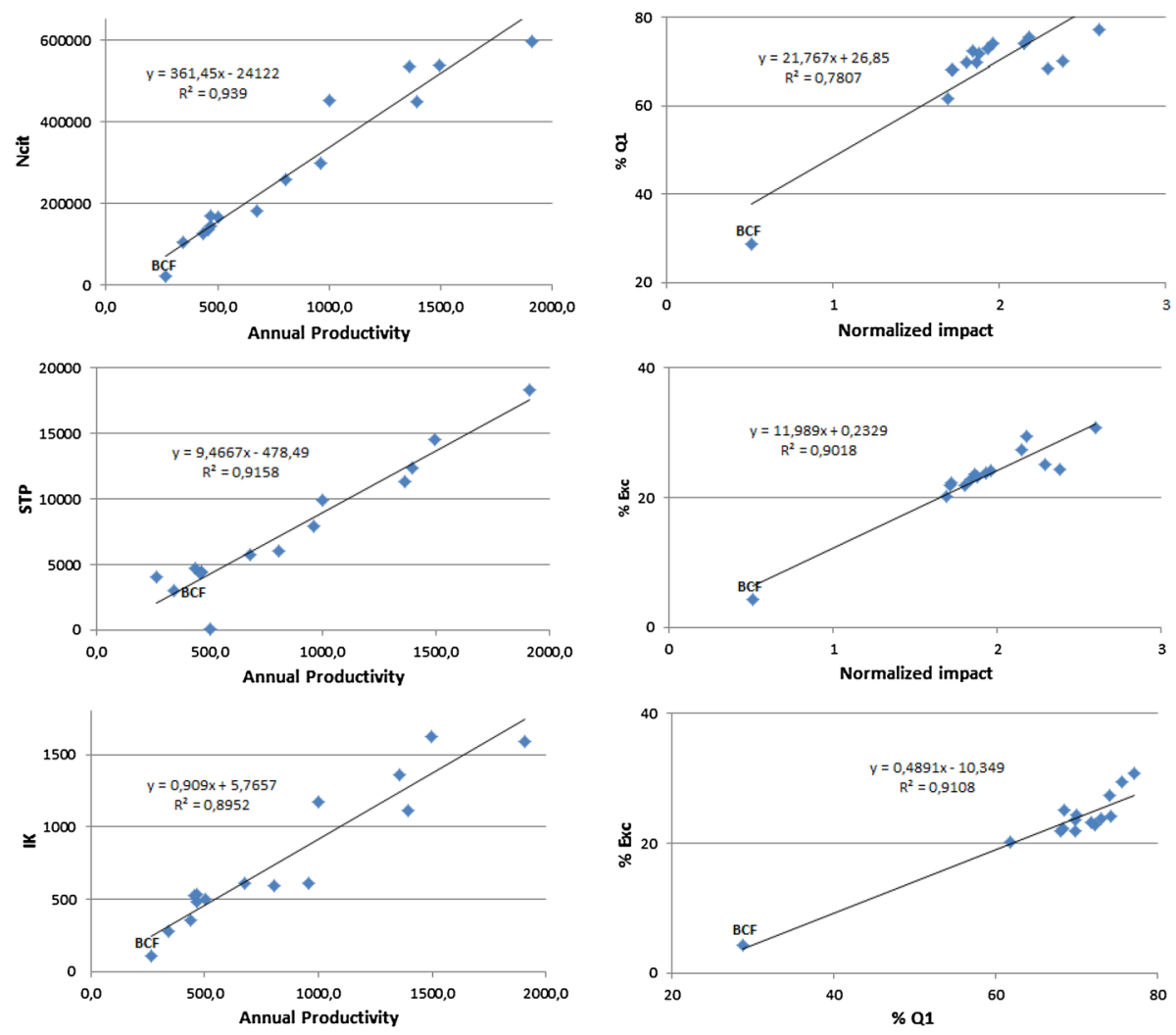

Fig. 2 Regression analysis of global indicators used to measure companies performances (Scopus, 2003-2013)

the publication efforts in medical journals are low compared with those developed by multinational companies, which could be evidence of two elements:

- An early stage of a big proportion of BioCubaFarma's research projects.

- An insufficient visibility of clinical research.

The first element is a strong point of BioCubaFarma, taking into account the new international context for Cuban economy, especially after the normalization of relationships between Cuba and United States governments. To enhance the coverage of national drug demands, to create solid worldwide partners and distributors, to introduce products in new markets, and to increase sales, requires also to have in plan the introduction of new products as a long time strategy, in order to build a sustainable way to development.

The second element is clearly a weakness. The results of clinical trials, especially when they revealed positive effects and involve huge amounts of patients, must be published in the best medical journals. This stimulates the interest of national and international research groups with the aim to test products in new population samples, which is also a guarantee for worldwide registration of products for sale.

Anyway, the low normalized impact of BioCubaFarma's output in each of the subject categories studied is a handicap. With low expenses in publicity, and even under 
Pharmacology, Toxicology and Pharmaceutics

$\square$ Spec $\longrightarrow$ Al $\longrightarrow$ N
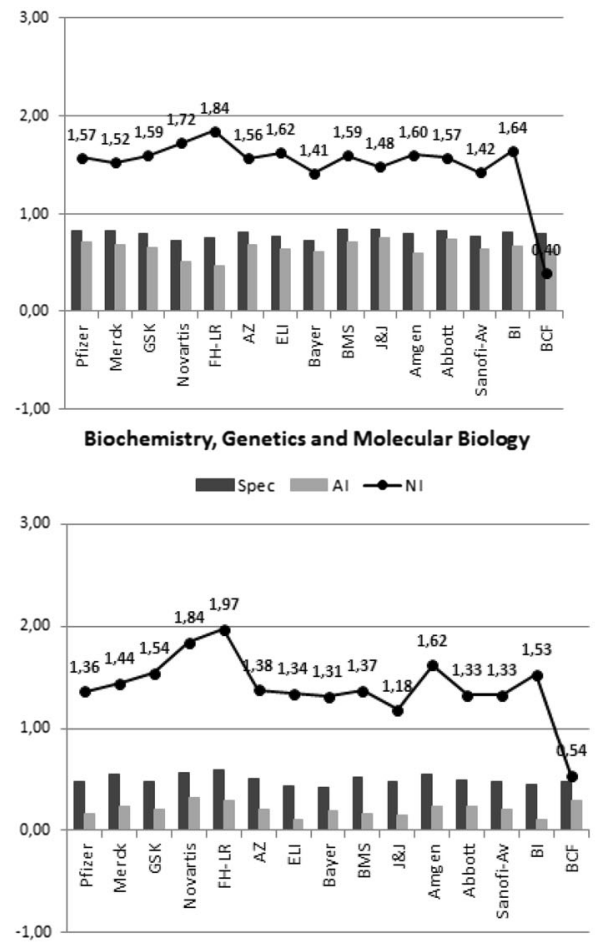

Immunology and Microbiology

Spec Al $\rightarrow$ NI

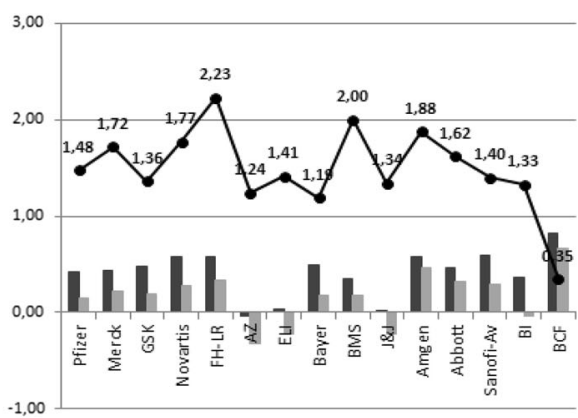

Medicine

$\square$ Spec $\longrightarrow$ AI $\longrightarrow$ N

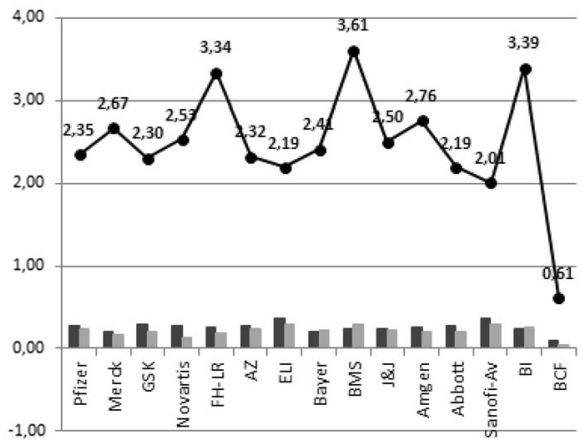

Fig. 3 Thematic Specialization, Attractivity Index and Normalized Impact of the studied companies in four selected Scopus subject categories (2003-2013)

constraints on resources resulting from the US embargo, it is necessary in terms of publication in high visible journals (\% Q1) to increase the values observed in Fig. 4, with the aim to revert this behaviour.

BioCubaFarma shown the highest values of leadership and the lowest values of international collaboration, expected visibility and excellence in all subject categories studied. Multinational companies exposed significant values of leadership in PTP (50-65\%) and BG\&MB (40-60\%), with low values of international collaboration $(<40 \%)$ in both categories; in contrast, international collaboration was high in I\&M ( $>40 \%)$ and Medicine ( $>40 \%$, with the solely exception of Amgen and Abbott Laboratories), categories where leadership values reached percentages around $40 \%$ or lowest. This dependency (or not) of international collaboration is apparently not related to the expected visibility of research: multinational companies shown higher values of publications in the most visible journals of the four categories, but the expected visibility is lowest in I\&M ( $\approx 40-60 \%)$ than in Medicine (60-80 \%). Anyway, Medicine is the subject category where BioCubaFarma's enterprises and multinational companies achieved the best measures of expected visibility and research excellence.

Inside the organization, the picture also offers interesting views. Only 18 enterprises contribute to the BioCubaFarma's scientific output covered by Scopus, and from them, 14 produced more than one paper per year (Table 3). Only seven presented an annual 


\section{Pharmacology, Toxicology and Pharmaceutics}

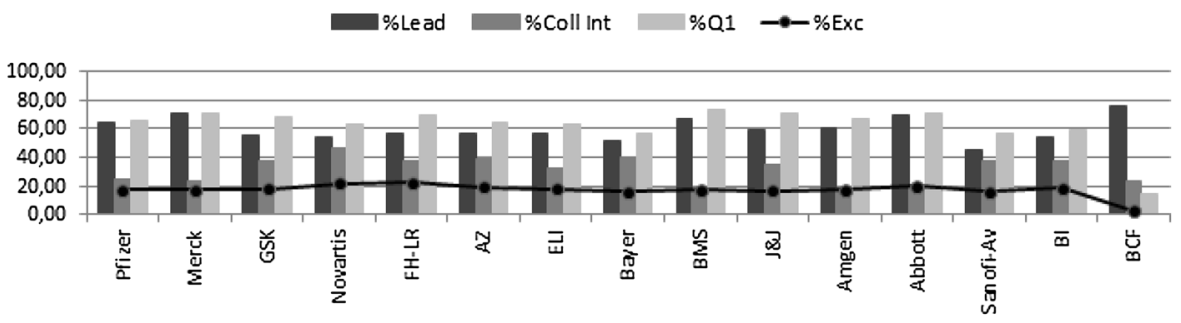

Immunology and Microbiology

\%Lead $\quad \%$ Coll int $\quad \% Q 1$ -

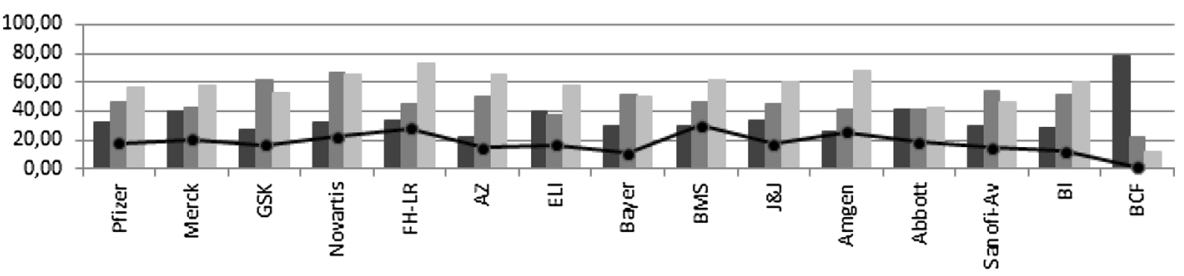

Biochemistry, Genetics and Molecular Biology

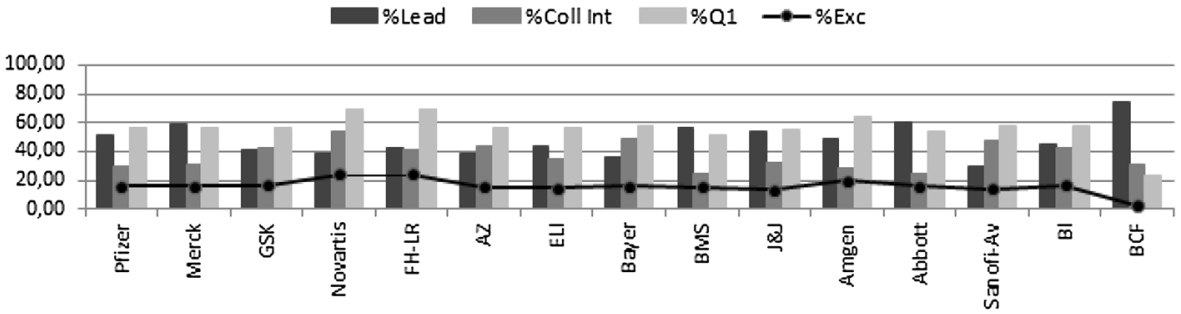

Medicine

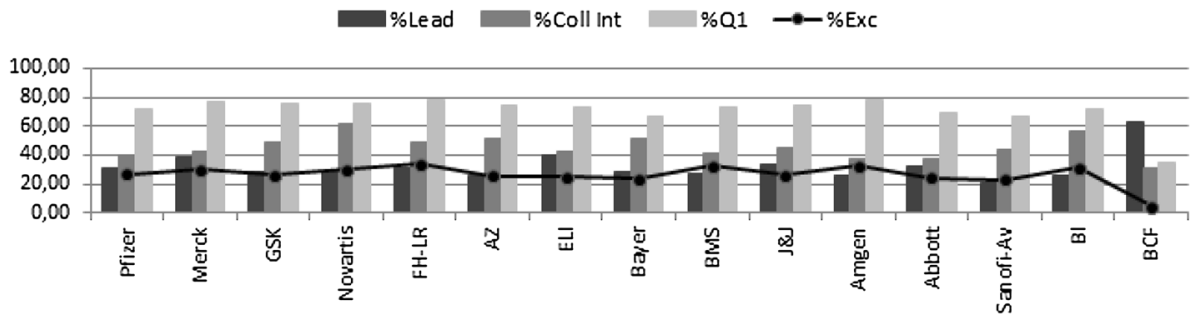

Fig. 4 Leadership, international collaboration, output in high visible journals and excellence of the studied companies in four selected Scopus subject categories (2003-2013)

productivity higher than 20 papers per year, which were the core of institutions responsible for the most relevant $R \& D$ achievements.

Producing more than $30 \%$ of BioCubaFarma's scientific output during the period 2003-2013, and receiving $35 \%$ of the citations to BioCubaFarma's papers, CIGB was the leader institution with an annual productivity of 82 papers per year, followed by CNIC 


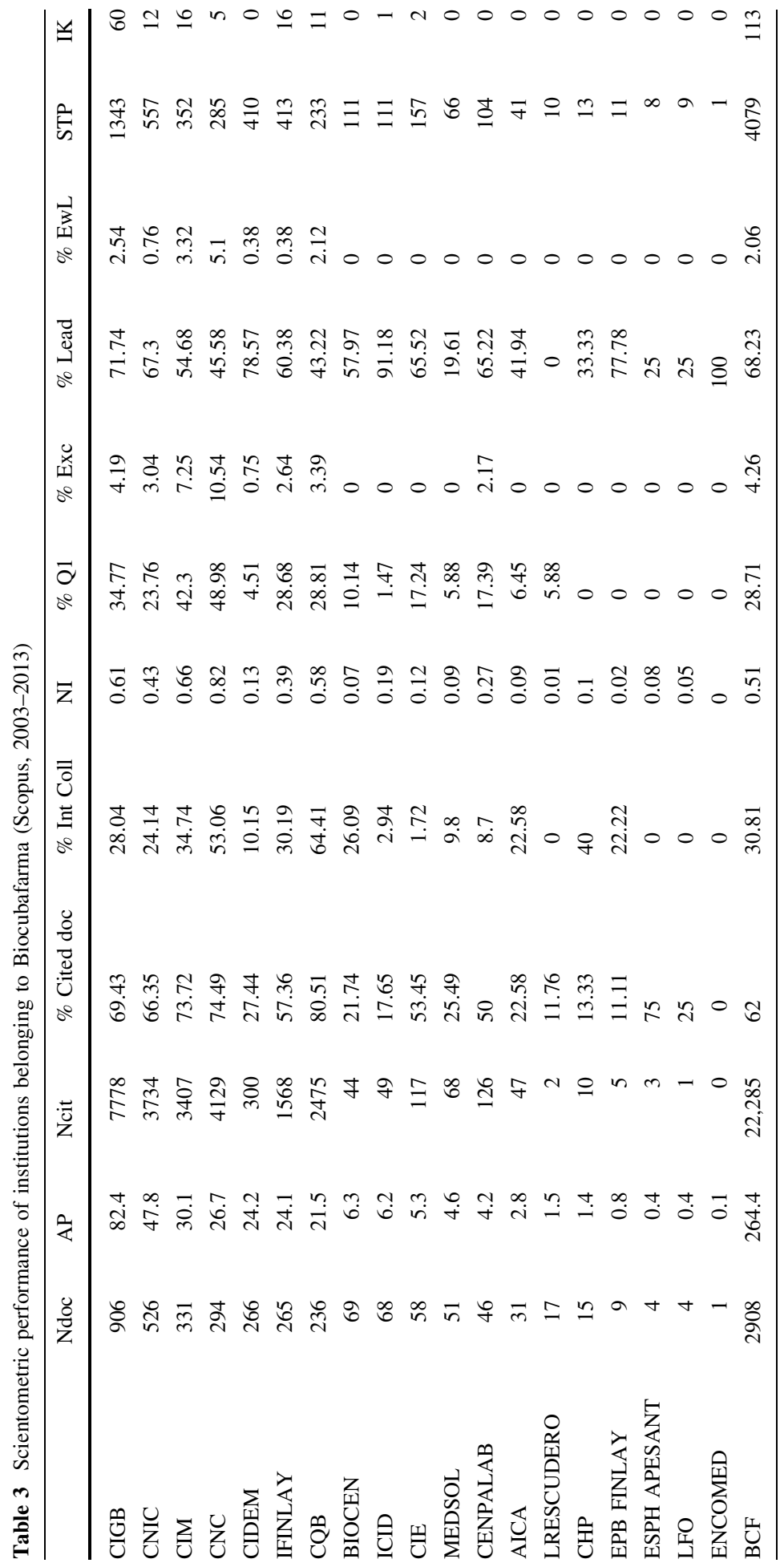




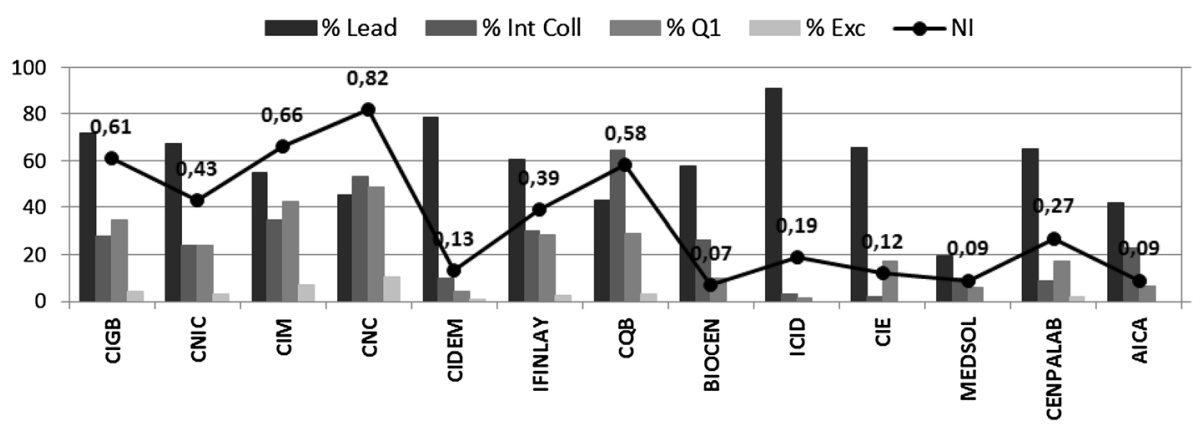

Fig. 5 Leadership, international collaboration, output in high visible journals, excellence and normalized impact of the most productive BioCubaFarma's companies (Scopus, 2003-2013)

(47.8), and CIM (30.1). CIGB was also leader in STP and IK, covering $33 \%$ of authors with contributions to BioCubaFarma's literature indexed by Scopus, and the $53 \%$ of articles cited in international patents.

The Center of Biomolecular Chemistry (CQB, former Center of Pharmaceutical Chemistry and currently unified to IFINLAY) presented the best proportion of cited articles $(80.5 \%)$, and the highest percentage of international collaboration (64.4\%). Cuban Neuroscience Center (CNC) occupied the second place in both indicators (74.5 and $53.1 \%$ ), but it was the leader in expected visibility (49\%) and the rest of the studied indicators: normalized impact (0.82), excellence (10.5\%), and excellence with leadership (5.1\%). Curiously, CNC's scientific output was covered by Neurology and Neurosciences, two subject categories avoided by the current study.

CNC, CIM, CIGB and CQB were the four most visible institutions, according to citation-based indicators (Fig. 5). CNC and CQB presented high values of international collaboration, while CIM and CIGB shown high values of leadership.

In general, the most productive institutions presented high values of leadership. The Q1 factor was not decisive in all cases in order to achieve a better citation-based performance. Only eight institutions had papers among the $10 \%$ of the most cited articles of a discipline. From them, only seven were leaders in some of these papers. And only eight exhibited at least one paper cited in international patents.

\section{Conclusions}

Biopharmaceutical industry had a protagonist role in the Cuban science system during the current century. BioCubaFarma was the second most productive Cuban institution according to The SCImago Institutions Rankings (SIR), thanks to the scientific output developed by its enterprises during the pre-foundational period (2003-2013).

Qualified human resources, innovative knowledge, leadership, high specialization in the field of vaccines development and non-dependence of international collaboration are strengths of the organization. However, the comparison with the 15 most productive multinational biopharmaceutical companies revealed strong relationships between values of expected and real visibility. Therefore, it is still necessary to increase the number of articles published in highly visible journals with the aim to achieve a better citation-based performance. 
More contributions from less-productive institutions, more clinical research published in medical journals and more collaboration with universities and health institutions could also have positive benefits for BioCubaFarma's pipelines and portfolios. The use of the studied indicators in further analysis of Cuban biopharmaceutical industry will offer the opportunity to follow the evolution of BioCubaFarma since the foundation to the future stages of development.

Acknowledgments This research was supported by 2015 Postdoctoral Short Visiting Program of the Spanish Instituto de Bienes y Políticas Públicas (IPP) from Consejo Superior de Investigaciones Científicas (CSIC).

\section{References}

Ammed, K. K. M., Gupta, R., \& Gupta, B. M. (2014). Pharmocology research in India: A scientometric analysis of publications output, 2003-2012. Indian Journal of Pharmaceutical Education and Research, 48(2), 16-34. doi:10.5530/ijper.48.2.4.

Araujo-Ruiz, J. A., Van Hooydonk, G., Torricella-Morales, R. G., \& Arencibia-Jorge, R. (2005). Cuban scientific articles in ISI Citation Indexes and CubaCiencias databases (1988-2003). Scientometrics, 65(2), 161-171. doi:10.1007/s11192-005-0265-4.

Arencibia-Jorge, R., \& de Moya-Anegón, F. (2010). Challenges in the study of Cuban scientific output. Scientometrics, 83(3), 723-737. doi:10.1007/s11192-009-0150-7.

Arencibia-Jorge, R., Vega-Almeida, R. L., Chinchilla-Rodríguez, Z., Corera-Álvarez, E., \& Moya-Anegón, F. (2012). Specialization patterns in the Cuban national health research. Revista Cubana de Salud Publica, 38(SUPPL. 5), 734-747. doi:10.1590/s0864-34662012000500007.

Bordons, M., \& Zulueta, M. A. (1997). Comparison of research team activity in two biomedical fields. Scientometrics, 40(3), 423-436. doi:10.1007/bf02459290.

Bordons, M., Barrigon, S., \& Mendez, A. (1996). Spanish investigation in international pharmacy and pharmacology journals from 1980-1989. Medicina Clinica, 106(2), 51-59.

Bordons, M., Zulueta, M. A., \& Barrigon, S. (1998). Scientific activity of the most productive Spanish research teams in pharmacology and pharmacy during the period 1986-1993 as covered by the Science Citation Index (SCI). Medicina Clinica, 111(13), 489-495.

Bornmann, L., Moya-Anegon, F., \& Leydesdorff, L. (2012). The new excellence indicator in the world report of the SCImago Institutions Rankings 2011. Journal of Informetrics, 6(2), 333-335.

Braun, T., \& Schubert, A. (1997). Dimensions of scientometric indicator datafiles-World science in 1990-1994. Scientometrics, 38, 175-204.

Calero, C., Van Leeuwen, T. N., \& Tijssen, R. J. W. (2007). Research cooperation within the bio-pharmaceutical industry: Network analyses of co-publications within and between firms. Scientometrics, 71(1), 87-99. doi:10.1007/s11192-007-1650-y.

Cami, J., Zulueta, M. A., Fernandez, M. T., Bordons, M., \& Gomez, I. (1997). Spanish scientific production in biomedicine and health sciences during the period 1990-1993 (Science Citation Index and Social Science Citation Index) and comparison to period 1986-1989. Medicina Clinica, 109(13), 481-496.

Cañedo Andalia, R., Pérez Machín, M., Guzmán Sánchez, M. V., \& Rodríguez Labrada, R. (2010). Approaches to visibility of science and scientific production of Cuba in the health area. ACIMED, 2l(1), 28-43.

Cañedo Andalia, R., Nodarse Rodríguez, M., Guerrero Pupo, J. C., Amell Muñoz, I., Small Chapman, M. C., \& Milord Ramírez, L. J. (2014). Cuban scientific production about health in international databases. Revista Cubana de Informacion en Ciencias de la Salud, 25(4), 442-451.

Cantner, U., \& Rake, B. (2014). International research networks in pharmaceuticals: Structure and dynamics. Research Policy, 43(2), 333-348. doi:10.1016/j.respol.2013.10.016.

Castillo, A., Caballero, I., \& Triana, J. (2013). Economic-financial management modeling for biotechnology enterprises in Cuba. Biotecnologia Aplicada, 30(4), 290-298.

Chinchilla-Rodríguez, Z., Arencibia-Jorge, R., de Moya-Anegón, F., \& Corera-Álvarez, E. (2015). Some patterns of Cuban scientific publication in Scopus: The current situation and challenges. Scientometrics, doi:10.1007/s11192-015-1568-8.

Cooper, R. S., Kennelly, J. F., \& Ordunez-Garcia, P. (2006). Health in Cuba. International Journal of Epidemiology, 35(4), 817-824. doi:10.1093/ije/dyl175. 
Ding, Z. Q., Ge, J. P., Wu, X. M., \& Zheng, X. N. (2013). Bibliometrics evaluation of research performance in pharmacology/pharmacy: China relative to ten representative countries. Scientometrics, 96(3), 829-844. doi:10.1007/s11192-013-0968-x.

Frame, J. D. (1977). Mainstream research in Latin America and the Caribbean. Interciencia, 2(3), $143-147$.

Glanzel, W. (2000). Science in Scandinavia: a bibliometric approach. Scientometrics, 48, 121-150.

Gomez, I., Fernandez, M. T., Bordons, M., \& Morillo, F. (2004). Spanish scientific output in Medicine in the years 1994-1999. Revista Clinica Espanola, 204(2), 75-88. doi:10.1157/13058801.

Gorraiz, J., \& Schloegl, C. (2008). A bibliometric analysis of pharmacology and pharmacy journals: Scopus versus Web of Science. Journal of Information Science, 34(5), 715-725. doi:10.1177/ 0165551507086991.

Guerrero-Bote, V., Olmeda-Gómez, C., \& Moya-Anegon, F. (2013). Quantifying the benefits of international scientific collaboration. Journal of the Association for Information Science and Technology, 64(2), 392-404.

Huang, M. C., Fang, S. C., \& Chang, S. C. (2011). Tracking R\&D behavior: Bibliometric analysis of drug patents in the Orange Book. Scientometrics, 88(3), 805-818. doi:10.1007/s11192-011-0400-3.

Kissin, I., \& Bradley, E. L. (2011). Top Journals Selectivity Index: Is it acceptable for drugs beyond the field of analgesia? Scientometrics, 88(2), 589-597. doi:10.1007/s11192-011-0403-0.

Kissin, I., \& Bradley, E. L. (2012). Top journals selectivity index and "me-too" drugs. Scientometrics, 91(1), 131-142. doi:10.1007/s11192-011-0556-x.

Lage, A. (2006). Socialism and the knowledge economy - Cuban biotechnology. Monthly Review-an Independent Socialist Magazine, 58(7), 50-58.

Lage, A. (2008). Connecting immunology research to public health: Cuban biotechnology. Nature Immunology, 9(2), 109-112. doi:10.1038/ni0208-109.

López Mola, E., Silva, R., Acevedo, B., Buxadó, J. A., Aguilera, A., \& Herrera, L. (2006). Biotechnology in Cuba: 20 years of scientific, social and economic progress. Journal of Commercial Biotechnology, 13(1), 1-11. doi:10.1057/palgrave.jcb.3050038.

Lopez, E., Silva, R., Acevedo, B., Buxado, J. A., Aguilera, A., \& Herrera, L. (2007). Taking stock of Cuban biotech. Nature Biotechnology, 25(11), 1215-1216. doi:10.1038/nbt1107-1215.

Minguillo, D., Tijssen, R., \& Thelwall, M. (2015). Do science parks promote research and technology? A scientometric analysis of the UK. Scientometrics, 102(1), 701-725. doi:10.1007/s11192-014-1435-Z.

Mohammadhassanzadeh, H., Samadikuchaksaraei, A., Shokraneh, F., Valinejad, A., Abolghasem-Gorji, H., \& Yue, C. (2010). A bibliometric overview of 30 years of medical sciences productivity in Iran. Archives of Iranian Medicine, 13(4), 313-317.

Moya-Anegon, F., Guerrero-Bote, V., Bornmann, L., \& Moed, H. F. (2013). The research guarantors of scientific papers and the output counting: A promising new approach. Scientometrics, 97, 421-434.

Natsukawa, T., Gemba, K., \& Ishida, S. (2013). The timing of interorganisational collaborations in an emerging biopharmaceutical field: Evidence from Japan in comparison to the remaining RNAi field. Technology Analysis \& Strategic Management, 25(5), 583-597. doi:10.1080/09537325.2013.785509.

Olmeda-Gomez, C., Perianes-Rodriguez, A., Ovalle-Perandones, M. A., \& Moya-Anegon, F. (2008). Comparative analysis of university-government-enterprise co-authorship networks in three scientific domains in the region of Madrid. Information Research-an International Electronic Journal, 13(3), 352.

Pérez Ones, I., \& Jover, J. N. (2009). Higher education and socio-economic development in Cuba: High rewards of a risky high-tech strategy. Science and Public Policy, 36(2), 97-101. doi:10.3152/ $030234209 \times 413900$.

Perianes-Rodriguez, A., Olmeda-Gomez, C., Ovalle-Perandones, M. A., Chinchilla-Rodriguez, Z., \& MoyaAnegon, F. (2011). R\&D collaboration in 50 major Spanish companies. Aslib Proceedings, 63(1), 5-27. doi:10.1108/00012531111103759.

Rehn, C., Kronman, U., \& Wadskog, D. (2007). Bibliometric indicators: Definitions and usage at Karolinska Institutet version 10. Stockholm: Karolinska Institutet University Library.

Sáenz, T. W. (2005). Biotechnology for medical applications: The Cuban experience. Science Technology \& Society, 10(2), 225-248. doi:10.1177/097172180501000203.

Sancho, R., Bernal, G., \& Gálvez, L. (1993). Approach to the Cuban scientific activity by using publication based quantitative indicators (1985-1989). Scientometrics, 28(3), 297-312. doi:10.1007/bf02026512.

Thompson, D. F., \& Nahata, M. C. (2012). Pharmaceutical science faculty publication records at researchintensive pharmacy colleges and schools. American Journal of Pharmaceutical Education, 76(9), 173.

Tijssen, R. J. W. (2009). Internationalisation of pharmaceutical R\&D: How globalised are Europe's largest multinational companies? Technology Analysis \& Strategic Management, 21(7), 859-879. doi:10. 1080/09537320903182330. 
Zacca-González, G., Vargas-Quesada, B., Chinchilla-Rodríguez, Z., \& De Moya-Anegón, F. (2014). Cuban scientific production in medicine and public health: Scopus 2003-2011. Transinformacao, 26(3), 281-293. doi:10.1590/0103-37862014000300005.

Zacca-González, G., Chinchilla-Rodríguez, Z., Vargas-Quesada, B., \& de Moya-Anegón, F. (2015). Patterns of communication and impact of the Cuban scientific output in public health. Revista Cubana de Salud Publica, 41(2), 200-216.

Zhao, Q. J., \& Guan, J. C. (2011). International collaboration of three 'giants' with the G7 countries in emerging nanobiopharmaceuticals. Scientometrics, 87(1), 159-170. doi:10.1007/s11192-010-0311-8. 